\title{
Correction to: \\ Child Development and the Community Environment: Understanding Overweight across the Income Gradient Child Obes 2017;13(6):479-489; DOI: 10.1089/chi.2017.0025
}

The article entitled, "Child Development and the Community Environment: Understanding Overweight across the Income Gradient" (Childhood Obesity 2017;13(6):479-489; DOI: 10.1089/chi.2017.0025), contained an error whereby the original source for Figure 1 was omitted from the legend. The corrected version of the Figure 1 legend is as follows:

Figure 1. The Six-Cs developmental ecological model of contributors to overweight and obesity. (From Harrison K, Bost KK, McBride BA, Donovan SM, Grigsby-Toussaint DS, Kim J, Jacobsohn G. Toward a developmental conceptualization of contributors to overweight and obesity in childhood: The Six-Cs model. Child Develop. Perspect. 2011;5: 50-58. Reprinted with permission from John Wiley \& Sons, Inc.)

The online version of the article has been corrected to reflect this change.

The authors regret this error. 